\title{
Effects of low-dose G-CSF formulation on hematology in healthy horses after long-distance transportation
}

\author{
Yoshiro ENDO ${ }^{1)}$, Seiji HOBO $^{2)}$, Kenji KOROSUE ${ }^{1)}$, Kenji OOTSUKA ${ }^{3)}$, Akira KITAUCHI ${ }^{4)}$, Risa KIKKAWA ${ }^{4)}$, \\ Yuichi HIDAKA ${ }^{4)}$, Mitsuyoshi $\mathrm{HAGIO}^{4)}$ and Nao TSUZUKI ${ }^{4) *}$ \\ ${ }^{1)}$ Miyazaki Yearling Training Farm, Japan Racing Association, 2347, Oharu, Hanagashima-cho, Miyazaki-shi, Miyazaki 880-0036, Japan \\ 2) Joint Faculty of Veterinary Medicine, Kagoshima University, 1-21-24, Korimoto, Kagoshima-shi, Kagoshima 890-0065, Japan \\ ${ }^{3)}$ Hidaka Training and Research Center, Japan Racing Association, 535-13, Nishicha, Urakawa-cho, Urakawa-gun, Hokkaido 057-0171, \\ Japan \\ 4)Laboratory of Veterinary Surgery, Faculty of Agriculture, University of Miyazaki, 1-1, Gakuen-kibanadai-nishi, Miyazaki-shi, Miyazaki \\ 889-2192, Japan
}

(Received 8 November 2014/Accepted 15 December 2014/Published online in J-STAGE 19 January 2015)

ABSTRACT. The present study evaluated the effects of single-dose filgrastim on hematology in 16 healthy horses after long-distance transportation. Horses were assigned to receive filgrastim $(0.23 \mu \mathrm{g} / \mathrm{kg}, \mathrm{SC}$, once; G-CSF group; $\mathrm{n}=8)$ or saline $(0.9 \% \mathrm{NaCl})$ solution $(0.3 \mathrm{~m} l$, $\mathrm{SC}$, once; control group; $\mathrm{n}=8) \leq 1 \mathrm{hr}$ before transportation. Horses were transported 2,530 $\mathrm{km}$ using commercial vans over the course of approximately $44 \mathrm{hr}$. Clinical examinations and hematologic analyses were performed on all horses before and after transportation. Because the post-transportation white blood cell counts and bacillary neutrophil to segmented neutrophil ratio were significantly higher in the GCSF group, filgrastim may have promoted the mobilization of neutrophils from marrow. Filgrastim deserves a further study for efficacy in preventing horse shipping fever.

KEY WORDS: filgrastim, horse, respiratory disease

doi: 10.1292/jvms.14-0586; J. Vet. Med. Sci. 77(4): 507-509, 2015

Fever associated with transportation is thought to be induced primarily by transportation stress and deterioration of the environment in the truck, and it is typically observed $20 \mathrm{hr}$ or more after the start of transportation [4, 7, 8]. The horse's bronchoalveolar region can become infected by opportunistic pathogens, including Streptococcus equi subsp. Zooepidemicus (S. zooepidemicus), a resident of the tonsillar tissues and trachea that is considered the main causative organism of shipping fever $[5,7,8,12]$.

We took notice of fluoroquinolone antibiotics, because $S$. zooepidemicus is sensitive to them and their antibacterial activity lasts about $24 \mathrm{hr}$. We reported that fever associated with transportation was significantly decreased by prophylactic administration of $5 \mathrm{mg} / \mathrm{kg}$ enrofloxacin (ERFX) [10] and $2 \mathrm{mg} / \mathrm{kg}$ marbofloxacin (MRFX) [2, 3]. However, regarding the use of an antimicrobial agent, there is the problem of onset of resistant bacteria. Also, the prophylactic effect of antimicrobial agents during transportation has not been established for periods of transportation of more than $24 \mathrm{hr}$.

On the other hand, it is known that the G-CSF (granulocyte colony-stimulating factor) promotes granulocytic growth in marrow and mobilization to peripheral blood [1].

*Correspondence to: Tsuzuki, N., Laboratory of Veterinary Surgery, Faculty of Agriculture, University of Miyazaki, 1-1, Gakuen-kibanadai-nishi, Miyazaki-shi, Miyazaki 889-2192, Japan. e-mail: tsuzuki@cc.miyazaki-u.ac.jp

(C)2015 The Japanese Society of Veterinary Science

This is an open-access article distributed under the terms of the Creative Commons Attribution Non-Commercial No Derivatives (by-nc-nd) License $<$ http://creativecommons.org/licenses/by-nc-nd/3.0/>.
Filgrastim, nartograstim, lenograstim and others, are sold as G-CSF formulations, and are applied for neutropenia occurring during chemotherapy for tumors in the field of human medicine [1]. Although a formulation has been applied to alloimmune neonatal neutropenia and neonatal isoerythrolysis in the field of equine medicine [11], application of G-CSF formulations has not advanced because they were too expensive to use for horses. However, in recent years, generic drug products have been released and have been priced such that they can be applied in equine medical care. According to a previous investigation, serum G-CSF was significantly high in horses that developed transportation-associated fever [6]. Therefore, an increase level of G-CSF represents one of the natural healing responses and is thought to be a condition suitable for exclusion of $S$. zooepidemicus. However, there are, to our knowledge, no previous reports of the effect of a G-CSF formulation during transportation.

In the present study, we applied filgrastim, which was one of the G-CSF formulations for horses, and investigated the effects of it on hematology in healthy horses after longdistance transportation.

Sixteen clinically healthy Thoroughbred yearlings were used for this experiment. The horses were divided into 2 groups of 8 horses each: a filgrastim administration group (G-CSF group; 4 males, 4 females; age, 1 year old; body weight [mean \pm standard deviation (SD)], $429 \pm 22 \mathrm{~kg}$ ) and a control group ( 3 males, 5 females; age, 1 year old; body weight [mean $\pm \mathrm{SD}$ ], $421 \pm 25 \mathrm{~kg}$ ). The horses in the 2 groups were administered, by subcutaneous administrations, G-CSF (Filgrastim BS $300 \mu \mathrm{g}$ Syringe for Inj. MOCHIDA, Tokyo, Japan) at $0.23 \mu \mathrm{g} / \mathrm{kg}$ or saline (Otsuka Saline Injection, To- 
Table 1. Rectal temperatures and blood parameters before and after transportation in horses dosed prophylactically with filgrastim

\begin{tabular}{|c|c|c|c|c|c|}
\hline \multirow[b]{2}{*}{ Group } & \multirow{2}{*}{$\begin{array}{c}\text { Sampling } \\
\text { (elapsed time) }\end{array}$} & \multirow{2}{*}{$\begin{array}{c}\text { Rectal temperature } \\
\left({ }^{\circ} \mathrm{C}\right)\end{array}$} & \multicolumn{3}{|c|}{ Peripheral blood } \\
\hline & & & WBC $\left(/ \mathrm{mm}^{3}\right)$ & $\mathrm{N} / \mathrm{L}$ ratio & $\begin{array}{l}\text { Bacillary neutrophil to } \\
\text { segmented neutrophil ratio }\end{array}$ \\
\hline \multirow[t]{6}{*}{ Control } & Before transportation $(0 \mathrm{hr})$ & 38.0 & 12,295 & 1.12 & 0.02 \\
\hline & & $(37.4-38.6)$ & $(8,640-16,480)$ & $(0.63-1.91)$ & $(0.00-0.12)$ \\
\hline & After transportation $(48 \mathrm{hr})$ & 38.6 & $9,300^{\mathrm{a}}$ & 1.12 & $0.02^{\mathrm{cD}}$ \\
\hline & & $(38.0-39.0)$ & $(8,000-12,200)$ & $(0.78-1.54)$ & $(0.00-0.05)$ \\
\hline & Day after transportation ( $72 \mathrm{hr})$ & 38.2 & 11,550 & 1.12 & 0.03 \\
\hline & & $(37.6-38.4)$ & $(8,100-14,300)$ & $(0.81-1.60)$ & $(0.00-0.10)$ \\
\hline \multirow[t]{6}{*}{ G-CSF } & Before transportation $(0 \mathrm{hr})$ & 38.1 & 13,545 & $0.92^{\mathrm{b}}$ & 0.01 \\
\hline & & $(37.6-38.7)$ & $(8,930-16,280)$ & $(0.63-1.33)$ & $(0.00-0.17)$ \\
\hline & After transportation ( $48 \mathrm{hr}$ ) & 38.6 & $13,500^{\mathrm{a}}$ & $1.91^{\mathrm{b}}$ & $0.10^{\mathrm{D}}$ \\
\hline & & $(38.0-39.0)$ & $(10,200-19,600)$ & $(1.22-3.05)$ & $(0.07-0.17)$ \\
\hline & Day after transportation $(72 \mathrm{hr})$ & 38.2 & 12,400 & 1.28 & $0.06^{\mathrm{c}}$ \\
\hline & & $(38.0-38.3)$ & $(8,400-13,700)$ & $(0.76-1.69)$ & $(0.04-0.09)$ \\
\hline
\end{tabular}

Data are expressed as the median (range), a, b, c, D Values with the same superscript letters are significantly (large letter, $P<0.01$; small letters, $P<0.05$ ) different according to the Steel-Dwass test.

kyo, Japan) at $0.3 \mathrm{ml}$, respectively. These doses were determined based on our preliminary experiment using 6 healthy Thoroughbreds. As a result of trying 3 different doses $(0.15$ $\mu \mathrm{g} / \mathrm{kg}, 0.23 \mu \mathrm{g} / \mathrm{kg}$ or $0.31 \mu \mathrm{g} / \mathrm{kg}$ ), the Tukey-Kramer test revealed that neutrophils were significantly increased 1 day and 2 days after administration of filgrastim at $0.23 \mu \mathrm{g} / \mathrm{kg}$ or more. When we gave filgrastim to 6 horses subcutaneously at $0.23 \mu \mathrm{g} / \mathrm{kg}$, the level of neutrophils at 1 day $(5,702 \pm 914$ $\left./ \mathrm{mm}^{3}\right)$ and 2 days $\left(4,902 \pm 1,128 / \mathrm{mm}^{3}\right)$ after administration significantly increased as compared with the value before administration (3,185 $\pm 914 / \mathrm{mm}^{3}$, data are expressed mean $\pm \mathrm{SD}$ ). Drugs were administrated no more than $1 \mathrm{hr}$ before the vans departed.

The departure point was HBA Hokkaido Sales Complex, and the destination was the JRA Miyazaki Yearling Training Farm. The duration of transportation was approximately $44 \mathrm{hr}$, and the distance was $2,530 \mathrm{~km}$. The land portion of the route was $2,420 \mathrm{~km}$ (expressway $2,320 \mathrm{~km}$ and national highway $100 \mathrm{~km}$ ), and the sea portion of the route was 110 $\mathrm{km}$. We used a large ferry for the sea portion of the route (from Hakodate Port in Hokkaido Prefecture to Aomori Port in Aomori Prefecture); the ferry trip took $3 \mathrm{hr}$ and $30 \mathrm{~min}$.

We used 3 commercial vans, each of which could be loaded with 6 horses and was designed exclusively for horse transportation. The structure of the vans was the same for all 3 . To prevent the horses from lowering their heads and getting injured, they were tied to a wall of the vans with ropes during transportation and break times. The horses were fed 4 times during transportation (at comfort stops $6 \mathrm{hr}, 21 \mathrm{hr}, 30$ $\mathrm{hr}$ and $41 \mathrm{hr}$ after the start of transportation); they were individually fed assorted types of feed at $1 \mathrm{~kg} / \mathrm{head}$. Water was always in free supply. Travel breaks were taken for about 15 to $30 \mathrm{~min}$ every $4 \mathrm{hr}$, and the insides of the trucks were ventilated at every break. After transportation, all horses were put out to pasture for $4 \mathrm{hr}$.

Before, during and after transportation, the horses were also examined by ocular inspection and palpation for the presence of any locomotive or digestive system signs associ- ated with the medication (G-CSF or saline). Rectal temperature was taken with a mercury thermometer just before and just after transportation and at one day after arrival.

Blood samples were collected from the jugular veins of the animals before transportation, after transportation and the day after transportation in plain blood collection tubes (VP-P100K, Terumo, Tokyo, Japan) and tubes containing EDTA (VC-C50, Terumo). The EDTA blood was used to measure the peripheral white blood cell (WBC) count by automatic hemocytometer (K-4500, Sysmex, Kobe, Japan). The EDTA blood also was used to calculate the neutrophil to lymphocyte ratio (N/L ratio) and the bacillary neutrophil to segmented neutrophil ratio after preparation of smears by a fixation method (Diff-Quick 16920, Sysmex). Two hundred cells per representative area were counted, and the N/L ratio and the bacillary neutrophil to segmented neutrophil ratio were calculated.

Some data did not show normal distributions; thus, we used nonparametric tests for statistical analysis. Data were expressed as a median and range. After performing the Friedman test, some data showed marginal significance. A multiple comparisons test (Steel-Dwass) was performed for the data that showed marginal significance by the Friedman test. Values of $P<0.05$ were considered significant.

No side effects, including locomotive or digestive system signs, were associated with the medications (G-CSF or saline) before, during or after transportation.

In comparisons between control group and G-CSF group, no significant differences were found in the various measurement values before transportation (Table 1). After transportation $(48 \mathrm{hr})$, rectal temperatures did not differ significantly among the 2 groups, with the temperatures being $38.6^{\circ} \mathrm{C}$ $(38.0-39.0)$ in the G-CSF group and $38.6^{\circ} \mathrm{C}(38.0-39.0)$ in the control group. However, the WBC counts and bacillary neutrophil to segmented neutrophil ratio were significantly higher in the G-CSF group compared with those in the control group after transportation (48 hr). Furthermore, the bacillary neutrophil to segmented neutrophil ratio was also 
significantly higher in the G-CSF group the day after transportation (72 hr) compared with that in the control group after transportation (48 hr). In the G-CSF group, the N/L ratio after transportation ( $48 \mathrm{hr}$ ) was significantly higher than that before transportation $(0 \mathrm{hr})$. In addition, none of the numerical values exhibited a sex difference.

In the humans, side effects, such as headache, fever and back pain, have been reported according to dosage of a GCSF formulation [9]. However, no side effects, including signs of the locomotive and digestive systems, were observed before, during or after transportation in the horses administered filgrastim in the present study. Therefore, we surmise that filgrastim is safe for subcutaneous administration (at $0.23 \mu \mathrm{g} / \mathrm{kg}$ ) just before transportation in young racehorses.

Because none of the horse developed shipping fever in the control group, no difference was found in temperature between the groups. The WBC counts and bacillary neutrophil to segmented neutrophil ratio just after transportation (48 hr) showed a significantly high value in the G-CSF group. Furthermore, the bacillary neutrophil to segmented neutrophil ratio was also significantly higher in the G-CSF group the day after transportation ( $72 \mathrm{hr}$ ) compared with that in the control group after transportation $(48 \mathrm{hr})$. Neutrophil mature into segmented neutrophils from bacillary neutrophils in the final stage of differentiation [1]. Both bacillary neutrophils and segmented neutrophils combat infections. However, a high ratio of bacillary neutrophils means that more active mobilization of neutrophils is being accomplished from marrow. In the G-CSF group, the N/L ratio after transportation (48 hr) was significantly higher than that before transportation $(0 \mathrm{hr})$. Thus, when filgrastim was given, granular leukocytes (above all neutrophils) were mobilized by marrow, and it was surmised that the horses being transported were in a state in which natural immunity was activated. In this study, the effect was sufficient with doses $(0.23 \mu \mathrm{g} / \mathrm{kg})$ much lower than conventional doses (1.4-3.5 $\mu \mathrm{g} / \mathrm{kg})$ [11]. Because the G-CSF formulation was applied to healthy horses in which myelosuppression did not occur in the present study, it was thought that even low doses of G-CSF were effective. Therefore, it was thought that G-CSF formulation are applicable to horses from the standpoint of cost.

In a previous study, it was thought that transport adversely affected the normally effective mucosal defence mechanism (e.g., ciliary motility) in the airways, leading to invasion by S. zooepidemicus (a common commensal microorganism in the equine tonsil and nasopharynx) into the lower airways, thus inducing acute lower airway inflammation in the affected horses [8]. The present study suggests that administration of filgrastim just before transportation activates natural immunity for more than $48 \mathrm{hr}$ and can protect against invasion by $S$. zooepidemicus.

In conclusion, it was thought that filgrastim promoted the mobilization of neutrophils from marrow to peripheral blood in healthy Thoroughbred yearlings. The efficacy of administration of filgrastim just before transportation in preventing horse fever associated with transportation is worthy of a further study.

\section{REFERENCES}

1. Aapro, M. S., Cameron, D. A., Pettengell, R., Bohlius, J., Crawford, J., Ellis, M., Kearney, N., Lyman, G. H., Tjan-Heijnen, V. C., Walewski, J., Weber, D. C., Zielinski C., European Organisation for Research and Treatment of Cancer (EORTC) Granulocyte Colony-Stimulating Factor (G-CSF) Guidelines Working Party. 2006. EORTC guidelines for the use of granulocyte-colony stimulating factor to reduce the incidence of chemotherapy-induced febrile neutropenia in adult patients with lymphomas and solid tumours. Eur. J. Cancer 42: 2433-2453. [Medline] [CrossRef]

2. Endo, Y., Tsuchiya, T., Omura, T., Nakai, K., Korosue, K., Ishimaru, M., Ishikawa, Y. and Hobo, S. 2014. Effects of preshipping marbofloxacin administration on fever and blood properties in healthy Thoroughbreds transported a long distance. $J$. Vet. Med. Sci. 77: 75-79. [Medline] [CrossRef]

3. Endo, Y., Tsuchiya, T., Akiyama, K., Takebe, N., Nakai, K., Korosue, K., Ishimaru, M., Tsuzuki, N. and Hobo, S. 2014. Comparison of the occurrence of transportation-associated fever in 2 years old Thoroughbreds before and after introduction of prophylactic marbofloxacin administration. J. Equine Sci. 25: 79-81. [Medline] [CrossRef]

4. Hobo, S., Kuwano, A. and Oikawa, M. 1995. Respiratory change in horses during automobile transportation. J. Equine Sci. 6: 135-139. [CrossRef]

5. Ito, S., Hobo, S., Eto, D. and Sato, H. 2001. Bronchoalveolar lavage for the diagnosis and treatment of pneumonia associated with transport in Thoroughbred racehorses. J. Vet. Med. Sci. 63: 1263-1269. [Medline] [CrossRef]

6. Momoi, Y., Kato, H., Youn, H. Y., Aida, H., Takagi, S., Watari, T., Goitsuka, R., Tsujimoto, H. and Hasegawa, A. 1996. Elevation of serum G-CSF level in horses with transportation-induced fever. J. Vet. Med. Sci. 58: 537-541. [Medline] [CrossRef]

7. Oikawa, M. and Kusunose, R. 1995. Some epidemiologocal aspects of equine respiratory disease associated with transport. J. Equine Sci. 6: 25-29. [CrossRef]

8. Oikawa, M., Takagi, S., Anzai, R., Yoshikawa, H. and Yoshikawa, T. 1995. Pathology of equine respiratory disease occurring in association with transport. J. Comp. Pathol. 113: 29-43. [Medline] [CrossRef]

9. Sveikata, A., Gumbrevičius, G., Seštakauskas, K., Kregždytė, R., Janulionis, V. and Fokas, V. 2014. Comparison of the pharmacokinetic and pharmacodynamic properties of two recombinant granulocyte colony-stimulating factor formulations after single subcutaneous administration to healthy volunteers. Medicina (Kaunas) 50: 144-149. [Medline] [CrossRef]

10. Tsuchiya, T., Hobo, S., Endo, Y., Narita, S. and Sakamoto, K. 2012. Effects of a single dose of enrofloxacin on body temperature and tracheobronchial neutrophil count in healthy Thoroughbreds premedicated with interferon- $\alpha$ and undergoing long-distance transportation. Am. J. Vet. Res. 73: 968-972. [Medline] [CrossRef]

11. Wong, D. M., Alcott, C. J., Clark, S. K., Jones, D. E., Fisher, P. G. and Sponseller, B. A. 2012. Alloimmune neonatal neutropenia and neonatal isoerythrolysis in a Thoroughbred colt. J. Vet. Diagn. Invest. 24: 219-226. [Medline] [CrossRef]

12. Yoshikawa, H., Yasu, T., Ueki, H., Oyamada, T., Oishi, H., Anzai, T., Oikawa, M. and Yoshikawa, T. 2003. Pneumonia in horses induced by intrapulmonary inoculation of Streptococcus equi subsp. zooepidemicus. J. Vet. Med. Sci. 65: 787-792. [Medline] [CrossRef] 